\title{
Age stratification and cohort effects in scholarly communication: A study of social sciences
}

\author{
Cassidy R. Sugimoto ${ }^{1 *}$, Thomas J. Sugimoto ${ }^{2}$, Andrew Tsou $^{1}$, Staša Milojević ${ }^{1}$, Vincent Larivière ${ }^{3}$ \\ ${ }^{1}$ School of Informatics and Computing, Indiana University Bloomington, IN 47405, USA \\ ${ }^{2}$ Center for Evaluation and Educational Policy, Indiana University Bloomington, IN 47405, USA \\ ${ }^{3}$ École de bibliothéconomie et des sciences de l'information, Université de Montréal, QC, Canada \\ ${ }^{4}$ Observatoire des sciences et des technologies, Université du Québec à Montréal, QC, Canada \\ *corresponding author: sugimoto@indiana.edu
}

\begin{abstract}
Aging is considered to be an important factor in a scholar's propensity to innovate, produce, and collaborate on high quality work. Yet, empirical studies in the area are rare and plagued with several limitations. As a result, we lack clear evidence on the relationship between aging and scholarly communication activities and impact. To this end, we study the complete publication profiles of more than 1000 authors across three fields-sociology, economics, and political science-to understand the relationship between aging, productivity, collaboration, and impact. Furthermore, we analyze multiple operationalizations of aging, to determine which is more closely related to observable changes in scholarly communication behavior. The study demonstrates that scholars remain highly productive across the life-span of the career (i.e., 40 years), and that productivity increases steeply until promotion to associate professor and then remains stable. Collaboration increases with age and has increased over time. Lastly, a scholar's work obtains its highest impact directly around promotion and then decreases over time. Finally, our results suggest a statistically significant relationship between rank of the scholar and productivity, collaboration, and impact. These results inform our understanding of the scientific workforce and the production of science.
\end{abstract}

\section{INTRODUCTION}

Aging is considered to be an important factor in researchers' creativity, productivity, and collaborative behavior. In their seminal chapter on age stratification in science, Merton and Zuckerman (1972) reflected: "It is an exemplary question for the sociology of science directing us to one form of interaction between the social structure and the cognitive structure of science and inviting the thought that, in some of its aspects, the cognitive structure of a field may appreciably differ for sub-groups of scientists within it" (p. 555). They bemoaned the paucity of literature on age stratification and enumerated several areas of future work. Since this time, a number of studies have sought to examine the relationship between aging and scholarly performance, with the lifecycle of a scholar operationalized in several ways: including the biological aging of the scholar, cohort succession, and rank advancement.

\section{Modes of scholarly aging}

Perhaps the most intuitive form of aging is to measure the years since the birth of the scholar. This form of aging has been studied largely in relation to the receptivity of young minds to new ideas (Merton and Zuckerman 1972, p. 515). Aging is portrayed as something inherently negative; as Blackburn and Lawrence (1986) summarize: “...some college and university administrators tend to believe that as faculty members become older they will be less productive, less, creative, less innovative, less willing to adapt to a changing environment and less effective as teachers" (p. 265-266). The rigidity of older scholars to adapt to new ideas has been repeatedly reinforced (e.g., Stephan 1996; Planck 1949). 
These assertions are largely based on studies showing a negative correlation between chronological age and variables such as productivity, creativity, and impact (e.g., Lehman 1953; Simonton 1988). However, there is a great deal of complexity in these results, as it varies across disciplines (Abramo, D'Angelo, and Murgia 2015; Dubois, Rochet, and Schlenker 2013; Simonton 1988). In addition, there has been some indication that senior authors do not lag behind their junior colleagues when it comes to doing cuttingedge research (Milojević 2012) and that scientific discovery is becoming increasingly associated with older scholars (Sabharwal 2013a, p. 158). Others have suggested that the relationship between aging and scientific measurements is curvilinear (Cole 1979; Gingras, Larivière, Macaluso, and Robitaille 2008) or quadratic (Gonzalez-Brambila and Veloso 2007). Explanations for this have come at both the individualistic and system levels: that is, the notion that some scholarship and scholars may simply take more time (Stephan 1996) and others suggesting that the reward system in science disproportionately rewards productive scholars, leading to attrition of those not rewarded (Cole 1979). The current state of work on this dimension of aging shows large variation by disciplinary affiliation of those studied and time at which the study was conducted.

Others have argued that scholars within a cohort-that is, classed by year of doctoral matriculation, graduation, or the receipt of a first academic position-behave in ways similar to each other and distinct from previous or subsequent cohorts (O'Brien 2011), regardless of chronological age of the individual scholar. Cohort-succession is in line with the concept of codification or socialization-a phenomenon in which scholars are encumbered with their views of the discipline during their training and retain these throughout their career (Merton and Zuckerman 1972). One might also extend this to scholarly behaviors - the patterns taught during doctoral education may remain embedded in a scholar's work practices. As Stephan (1996) asserted, cohorts have varying levels of access to research, rates of obsolescence change, and the knowledge progression of the field at the time of entry may affect a scholar's approach to the field. However, few studies have examined, at a large scale, the degree to which approaches to scholarship vary systematically by cohort.

Rank advancement serves as a distinct way to identify career stage for scholars; given this, it is not uncommon for bibliometric analyses to display results by rank (e.g., Shaw and Vaughan 2008). Career aging - or rank advancement-theories assert that a scholar's behaviors may change as they meet various milestones in their career (O'Brien 2011). This differs from cohort-succession in that scholars may meet career milestones at a different rate than other scholars in their cohort. It has been suggested that, in a meritocratic system, rank advancement and productivity are highly correlated (Long, Allison, and McGinnis 1993), which may explain the gendered difference in rates and time to promotion, given the lower rates of research productivity among women (e.g., Long and Fox 1995; Sabharwal 2013b; Zuckerman 1987). It is, however, worth noting that these differences vanish when considering only younger scholars (van Arensbergen, van der Weijden, and van den Besselaar 2012). Other studies show modification in the emphasis on different forms of scholarship across rank (Sugimoto, Russell, Meho, and Marchionini 2008) and changes in productivity and author order through the career, with scholars largely deferring prestigious author positions to junior scholars (Long, McGinnis, and Allison 1980; Merton and Zuckerman 1972). Of course, the duties required of academics at various stages in their careers-e.g., teaching and service-also have an impact on research productivity (Sabharwal 2013a).

Each of the models of aging implies that careers are not stable, with inequalities increasing from time since receipt of a doctoral degree (Allison, Long, and Krauze 1982). One might note the Matthew effect at work, given that "because of feedback through recognition and resources, highly productive scientists maintain or increase their productivity, while scientists who produce very little produce even less later on" (Allison and Stewart 1974, p. 596). However, other studies have suggested that scholars choose and 
retain scholarly publication activities across their lifetime, regardless of aging (e.g., Bayer and Smart 1991; Sugimoto and Cronin 2012) or vary independent of aging (Cronin and Meho 2007). Therefore, a theory of aging must also take into account individuality in the model as well as how historical changes may affect life cycles (Jones 2005).

\section{Aging and measures of scholarly communication and impact}

Productivity (i.e., number of scholarly works) and impact (i.e., number of citations) have a long history of being used as proxies for success, i.e., as means to measure quantity and quality of scientific output. Publications counts are an oft-used proxy for levels of research activity (Stephan 1996) and can thus be used to estimate effects of aging on research productivity. For example, studies have estimated peaks of research prolificacy between 40-53 years of age (Bernier, Gill, and Hunt 1975; Simonton 1988; GonzalezBrambila and Veloso 2007); however, these studies suggest that both quality and quantity of output declines monotonically with age. Complexities to interpreting the results of productivity studies arise from the fact that a number of different methods have been used to calculate the relationship between productivity and aging (e.g., Allison and Stewart 1974) and the amount of variation explained in such studies is usually small (Stephan 1996).

Studies on the relationship between impact and age have produced many conflicting findings. Many of the earlier studies of citation impact were plagued with data collection problems, such as the inclusion of only the first author in the cited reference field of the Science Citation Index (Long, McGinnis, and Allison 1980). Cole (1979) found that the work of older scientists receives fewer citations; however, attempts to find the peak of impact have identified sweeping ranges: for example, Diamond (1986) estimated the peak of citations between 39 and 89 years of age. Gonzalez-Brambila and Veloso (2007) were more precise, pinpointing the citation peak at 56 years of age. Other scholars have concluded that scholarly impact is independent of age (Blackburn and Lawrence 1986; Oromoner 1977; Oster and Hamermesh 1998; Over 1988; Over 1989). A more recent study suggests a linear decrease in scientific impact per paper until age 50, at which time "the average number of papers in highly cited journals and among highly cited papers rises continuously until retirement" (Gingras, Larivière, Macaluso, and Robitaille 2008). This may suggest survival bias and cumulative impact (Long and McGinnis 1981; Merton 1968), as those who remain in the scientific enterprises are likely to be those who are receiving the most rewards of the enterprise. Of course, disciplinary differences contribute to this variability as well.

Science has also become, since the second half of the $20^{\text {th }}$ Century, increasingly collaborative (Larivière, Sugimoto, Tsou, and Gingras 2015; Milojević 2014; Wuchty, Jones, and Uzzi 2007). Although collaboration has been linked with many positive outcomes, including an increased likelihood that a paper will be accepted and a shortened time to promotion (Bayer and Smart 1991), it has also been argued that collaboration can be risky for junior scholars attempting to establish an independent research program (Fox and Faver 1984). This was reinforced by Bayer and Smart (1991), who found an increase in the number of collaboratively authored papers published over the course of an academic's career (by mid-career, more than one-half of the published papers in the sample of chemists were multiauthored). In addition, there is evidence that there is no link between collaborative activity and increased citations (Endenich and Trapp 2015), though it has been argued that there is a link between collaboration and productivity (Hu, Chen, and Liu 2014); a related finding is that elite scholars (that is, those with high publication and/or citation counts) have lower collaboration rates than other academics (Corley and Sabharwal 2010). However, it has also been argued that collaboration with foreign scholars does indeed lead to higher citation counts, and that collaboration activity is more relevant than a scholar's gender in this regard (Prozesky and Boshoff 2011). Ultimately, changing norms over time 
require renewed evaluations of the value of collaboration and differences in collaboration propensity by discipline and by gender (e.g., Larivière, Ni, Gingras, Cronin, and Sugimoto 2013; Mählck 2001).

As different disciplines have different knowledge production practices (Whitley 2000)--influenced by different norms, objects, and techniques of study--a scholar's discipline is a critical variable to consider when examining productivity, impact, and collaboration. Studies have drawn varying conclusions on the relevance of discipline to the age/publication (or discovery) interaction. Whereas Cole (1979) found relatively few disciplinary differences, Gonzalez-Brambila and Veloso (2007) found that the youngest scientists peak in health sciences and engineering, while the oldest peak in exact sciences and physics. Conversely, Simonton (1988) wrote that pure mathematics and theoretical physics can be considered young disciplines, whereas elongated curves have been witnessed for history, philosophy, and medicine. The social sciences are often excluded in these studies; with some exceptions (e.g., Abramo, D'Angelo, and Murgia 2015; Gingras, Larivière, Macaluso, and Robitaille 2008; Gonzalez-Brambila and Veloso 2007; Milojević 2012; Sabharwal 2013a; Wuchty, Jones, and Uzzi 2007), wherein hard sciences, social sciences, and (sometimes) humanities were taken into consideration. Specific social science fields under analysis included public administration (Corley and Sabharwal 2010; Sabharwal 2013b), information and/or library science (Cronin and Meho 2007; Shaw and Vaughan 2008; Sugimoto and Cronin 2012; Sugimoto, Russell, Meho, and Marchionini 2008), accounting (Endenich and Trapp 2015), economics (Oster and Hamermesh 1998), sociology (Oromoner 1977), and psychology (Over 1988; Over 1989). Some studies took more than one social science into account (e.g., Fox and Faver 1984 considered sociology, psychology, and economics). However, many only considered the hard sciences (Allison and Stewart 1974; Allison, Long, and Krauze 1982; Bayer and Smart 1991; Bernier, Gill, and Hunt 1975; Diamond 1986; Dubois, Rochet, and Schlenker 2013; Hu, Chen, and Liu 2014; Larivière, Ni, Gingras, Cronin, and Sugimoto 2013; Long and Fox 1995; Long, Allison, and McGinnis 1993; Long, McGinnis, and Allison 1980; Mählck 2001; Merton and Zuckerman 1972; O'Brien 2011; Prozesky and Boshoff 2011; van Arensbergen, van der Weijden, and van den Besselaar 2012; Whitley 2000). Even Lehman (1953), who considered 80 different occupations/disciplines, almost exclusively analyzed hard sciences, the arts, and even sports at the exclusion of the social sciences. The present study, therefore, takes disciplinary differences into account and focuses on the social sciences.

\section{Research questions}

There are many ways to conceptualize and operationalize aging and studies of science have failed to identify which model of aging is most predictive of changes in scholarly communication behaviors. Furthermore, differences have been found across time, by discipline, and by gender. Therefore, the following study seeks to examine the relationship between aging and scholarly communication and impact in three social science disciplines (economics, political science, and sociology), taking gender into account. Specifically, the following research questions will be addressed:

1. What is the relationship between aging and research productivity?

2. What is the relationship between aging and collaboration?

3. What is the relationship between aging and citation impact?

4. Which form of aging best relates to changes in productivity, collaboration, and impact?

This work will inform research evaluation exercises at the individual and institutional levels, as it explores the degree to which our current mechanisms for evaluating scholarship relate to aging and various aspects of scholarly communication practices and metrics. In particular, this work sheds light on the social sciences, a less researched area in the domain of scholarly aging studies. The comparison of multiple methods to analyze aging will inform future bibliometric studies, by providing an indication of 
the degree to which certain ways of operationalizing aging interact with scholarly communication variables. Finally, this work incorporates the full genre portolio-a major limitation in previous studies which relied on single-genre databases (e.g., Web of Science), rather than a comprehensive analysis of the authors' oeuvres.

\section{METHODS}

Studies of research productivity and impact in a life-cycle context have failed to produce conclusive results. Stephan summarized some of the limitations of those studies, including "measurement, the confounding of aging effects with cohort effects, and the availability of an appropriate database" (Stephan 1996). We have sought to address these limitations by exploring multiple operationalizations of aging, isolating cohort effects, and curating a comprehensive dataset. Historically, scientometric databases have tended to be homogeneous in terms of genre: the Web of Science, for example, historically only indexed journal articles. Although databases have become increasingly heterogeneous in recent years, they still lack the comprehensiveness that can be found on a curriculum vita (CV). As Dietz et al. (2000) persuasively argued, the CV provides a comprehensive detail of not only full publication data for an individual, but also professional changes: such as change in an institution or advancement in rank. It also has a fairly standardized format across country and discipline. CVs are therefore well situated for analysis of academic career trajectories.

Sample. A purposive sampling method was employed to select faculty members in the social sciences at elite research institutions. Specifically, active tenured and tenure-track faculty members at "top ten" (as determined by consulting lists published by U.S. News and World Report) programs in sociology, political science, and economics were selected for analysis. The lists of eligible faculty members were generated in August 2012. Official department webpages were consulted in order to generate the lists of faculty members, as well as to ascertain job titles; individual faculty webpages were then used to harvest CV links. If an individual's webpage did not contain a link to a CV (or if the person did not have a webpage), a Google search was employed to locate a current CV. Only full-time tenure-track faculty were included (i.e., lecturers, emeritus professors, research professors, and other non-tenure-track individuals were excluded). Some faculty members appeared multiple times within and across disciplines. Two economics faculty moved to another institution within the study; as did one sociologist. For these, duplicate publications were removed so that the publication was only counted a single time in the disciplinary analyses. One faculty member had a joint appointment in Economics and Sociology. For this individual, duplicate publications were not removed; that is, they were counted in both Economics and Sociology as this person would be considered a member of each disciplinary unit. The CVs for 115 faculty members were password-protected or could not be located: $20 \mathrm{CVs}$ were unavailable for the Sociology faculty (6.8\%), 70 for the Political Science faculty (16.4\%), and 25 for Economics faculty members (6.2\%). This resulted in the collection of 1002 CVs.

The focus on the faculty in leading research institutions is purposeful. We are aware that the results obtained for this group of researchers and scholars are not applicable to all the researchers. Researchers who work in less-research intense institutions need to be studied separately, since the allocation of their time between three main aspects of scholarship (i.e., research, teaching, and service) is different and their career trajectories are likely to follow different paths. However, the present study provides a foundation for studies of faculty in different types of institutions.

Aging data. As noted, this study examines three different types of aging: time since doctoral degree (professional aging), decade in which doctoral degree was earned (cohort aging), and analysis at rank (rank advancement). To identify both academic and cohort aging, CVs were coded according to the 
institution at which the individual received his/her doctoral degree and the year in which it was received. When these data were not available on the CV, we searched in ProQuest's Dissertations and Theses database. Years in which Ph.D. were conferred were determined in all cases for sociologists, for all but four political science faculty members, and for all save one economist. In an ideal scenario, actual age for the scholars would be available, to more fully distinguish between academic age and cohort aging. However, the year of doctoral degree is used here as the best proxy. We acknowledge that this limits the data analysis, as the operationalization of these two variables is quite similar. Cohort (as described in table 1) refers, therefore, to the decade in which a scholar received their doctoral degree, rather than the exact year (conceptualized as academic aging).

To analyze rank advancement as a form of aging, CVs were mined for the dates at which individuals attained various ranks (i.e., Assistant Professor, Associate Professor, and Professor). This is complicated by the fact that not everyone in the dataset achieved each of these ranks-some were hired as Associate Professors, some left academe as Assistants and returned as Professors-and some people omitted the dates at which they achieved ranks. Authors that were missing dates for earning Ph.D. or any applicable rank (e.g., Associate professor missing date they earned Assistant) were removed from analysis. This removed 179 of the 1002 originally identified authors. For univariate and bivariate analysis, cases were removed pair-wise (when relevant data was missing). Regression analysis removed cases when any variable was missing ( 814 analyzed). Table 1 provides a detailed list of the data for the descriptive and regression samples.

Table 1. Variables included in the dataset

\begin{tabular}{|l|r|r|}
\hline Variable & Descriptive Sample & Regression Sample \\
\hline Number of authors & 1002 & 814 \\
\hline Publications & 47,409 & 35,690 \\
\hline Female & $24.1 \%$ & $24.9 \%$ \\
\hline Discipline & & $36.7 \%$ \\
\hline Economics & $37.6 \%$ & $36.0 \%$ \\
\hline Political Science & $35.4 \%$ & $27.3 \%$ \\
\hline Sociology & $27.0 \%$ & $23.3 \%$ \\
\hline Current Rank & & $14.9 \%$ \\
\hline Assistant & $18.0 \%$ & $61.7 \%$ \\
\hline Associate & $14.4 \%$ & $0.6 \%$ \\
\hline Professor & $67.7 \%$ & $4.1 \%$ \\
\hline Cohort & & $14.8 \%$ \\
\hline 1950 's & $0.7 \%$ & $17.9 \%$ \\
\hline 1960 's & $5.0 \%$ & $22.0 \%$ \\
\hline 1970 's & $16.8 \%$ & $33.5 \%$ \\
\hline 1980 's & $19.7 \%$ & $7.0 \%$ \\
\hline 1990 's & $20.9 \%$ & 19.0 \\
\hline 2000 's & $30.4 \%$ & $(13.3)$ \\
\hline 2010 's & $5.9 \%$ & \\
\hline missing & $0.5 \%$ & 20.4 \\
\hline Mean & $(13.5)$ & \\
\hline (standard deviation) & & \\
\hline
\end{tabular}


As seen in Table 1, nearly $70 \%$ of the faculty members in the sample were full professors at the time of data collection. However, the majority of these individuals served, at some point in their career as first Assistant and then Associate professors. Therefore, in an analysis of aging, these people are included in the analysis at all ranks that they indicated (identifying their levels of productivity and collaboration at the time of rank). However, it is an acknowledged limitation that this introduces a form of survival bias in the analysis: we are, in this way, analyzing those Assistant and Associate professors who "survived" within the academic system to Full professor.

Publication data. Previous studies have relied on data from WoS and, in doing so, have omitted valuable contributions (e.g., Gonzalez-Brambila and Veloso 2007) (i.e., genres and works not indexed by WoS). Given the role of non-source items in the social sciences (Chi 2014; Nederhof 2006; Nederhof, van Leeuwen, and van Raan 2010), curriculum vitae were manually examined and complete lists of publications gathered. Journal articles that were not subjected to formal peer review were omitted (e.g., editorials), as were book reviews, working papers, and works classified as "in progress," "submitted," "forthcoming" or "under review." Lectures and other oral presentations were generally excluded, unless they were later published in a formal venue. Privately prepared papers (for example, reports to government commissions) were also excluded. Included were journal articles, book chapters, books, conference papers, encyclopedia entries, and dictionary entries. These were included as items that were fairly standard across all three disciplines and easily distinguished on the CV. Genres were classified using the classifications on authors' CVs, in the cases where such information was available (e.g., many scholars organize the CV by genre type). In cases where the publications weren't classified, Google searches were used to identify the genre type. The item was excluded from further analysis if the type of genre could not be ascertained. Dates of all publications were recorded. Publications marked as "forthcoming" or "in press" were excluded. No effort was made to validate or update the CVs.

Citation and Impact Factor data. Data on citations and Impact Factors of journals in which papers were published was compiled using Thomson Reuters' Web of Science, which covers the Science Citation Index Expanded (SCIE), the Social Sciences Citation Index (SSCl), and the Arts and Humanities Citation Index $(\mathrm{AHCl})$. These databases only cover journal articles published in "international" peer-reviewed journals, so citation data could only be compiled for such types of documents. As researchers in the chosen fields are likely to publish books or in venues not indexed by the three citation indexes (Archambault et al. 2006; Larivière, Archambault, Gingras, and Vignola Gagné 2006), there is a large proportion of documents for which such citation data (61.6\%) and Impact Factor data (65.4\%) could not be obtained. There are slight disciplinary differences in this: for example, Impact Factors could be found for $42 \%$ of the publications in Economics, whereas they were only found for $25 \%$ of Political Science Publications and $30 \%$ of Sociology publications. This is a result both of the genre composition of these disciplines as well as coverage in Web of Science.

Analysis. All analyses were limited to the first forty years of a person's professional age (following earning a PhD). This was to ensure there were multiple authors in each age group. Productivity is defined by the average number of publications (of any genre) per year. Collaboration is defined by the percentage of publications with coauthors per year. In order to take into account the different citation practices of the various disciplines and specialties, Impact Factors (IF) and citations were fieldnormalized, by dividing the value obtained by each paper or journal by the average paper or journal of the same publication subfield, based on the National Science Foundation field classification.

The models regressed Ph.D. cohort decade, rank at time of publication, professional age at time of publication, discipline, gender, and year of publication against each dependent variable. Publications 
were nested by author using random intercepts for each author. All models were analyzed using SPSS version 22 using mixed models. Estimates for discipline show the average estimate relative to Sociology. Ph.D. cohort decade estimates are relative to 2010's. Rank at time of publication estimates are relative to full professor. As before, professional age at time of publication is the number of years since earning Ph.D. (0 being the year the degree was earned).

\section{RESULTS}

\section{Productivity and Aging}

To analyze the relationship between productivity and age, we examined the average number of publications per year. We conducted these analyses for three different operationalizations of age: cohort decade, rank, and professional age. To determine the best predictors for productivity, we employed regression analyses, using all three operationalizations of age, discipline, and gender as dependent variables. The above-mentioned analyses were carried out for all the publications regardless of genre. However, the literature on scholarly communication suggest not only that different disciplines prefer disseminating their knowledge claims using different genres (e.g., books, journal articles, conference papers), but that there might be change in genre preference over one's academic career. Thus, we carried out the analyses that examined productivity by genre (journal article, book chapter, book, conference paper, encyclopedia entry and dictionary entry).

Productivity is defined as the average of the number of publications divided by the professional age of each author (which thus equates to annual productivity). There are significant $(p<.0001)$ differences in productivity by cohort age, with decreasing average annual productivity between the 1950 and 2000s cohorts (Figure 1A). Given the low number of faculty in the data from the 1950s, some of this could be interpreted as a survival bias - that is, productive individuals were less likely to retire, move, or leave academe, and so remain in the data set. We have also found that there are statistically significant $(p<.0001)$ differences in productivity by rank, with increasing average annual productivity at each rank (i.e., Full professors are the most productive; Assistant professors the least). Figure 1B shows the average number of publications per year while an individual was at a given rank. This may also serve to explain the decreasing productivity by cohort age.
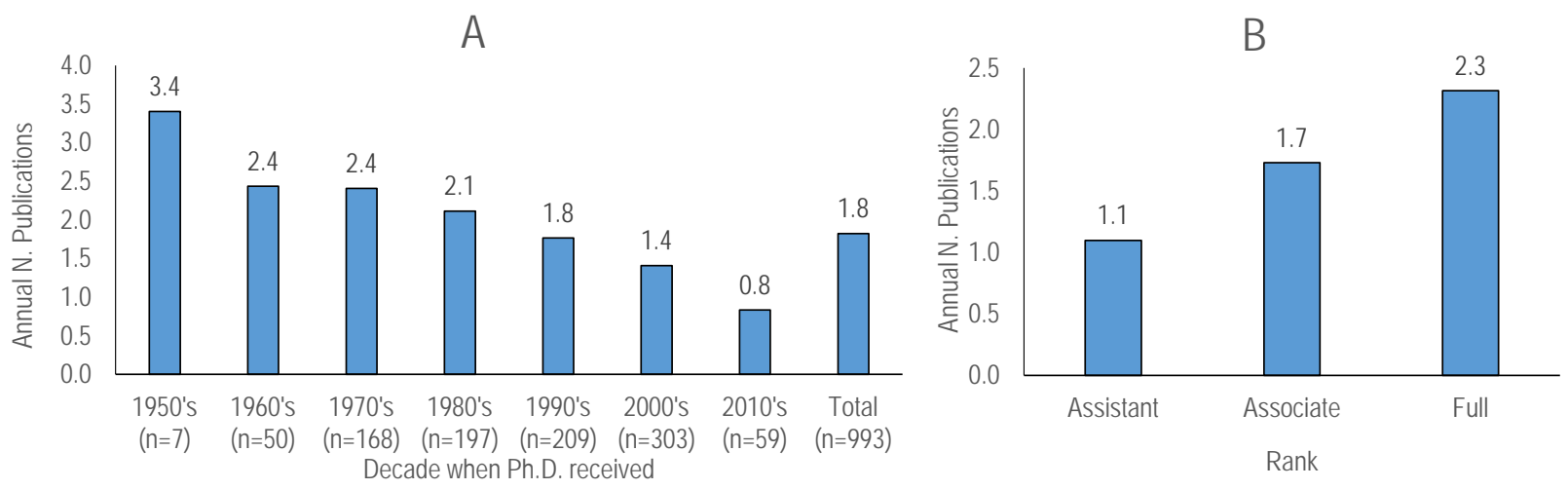

Fig 1 Annual number of publications. A) By decade of receipt of the doctoral degree, B) by professorial rank at time of publication

As one might expect from Figure $1 \mathrm{~A}$, the average number of publications per year at a given professional age (Figure 2) demonstrates that older faculty members have a greater output than their younger colleagues. More specifically, results show that faculty members begin at a low production, increase to 
about two publications per year by their fifth year and continue to increase until their $20^{\text {th }}$ year, when they stabilize in terms of productivity at 2.5 publications per year. This remains stable for about 40 years following the receipt of the doctoral degree. This suggests that faculty who remain in academe maintain productivity across the academic lifecycle.

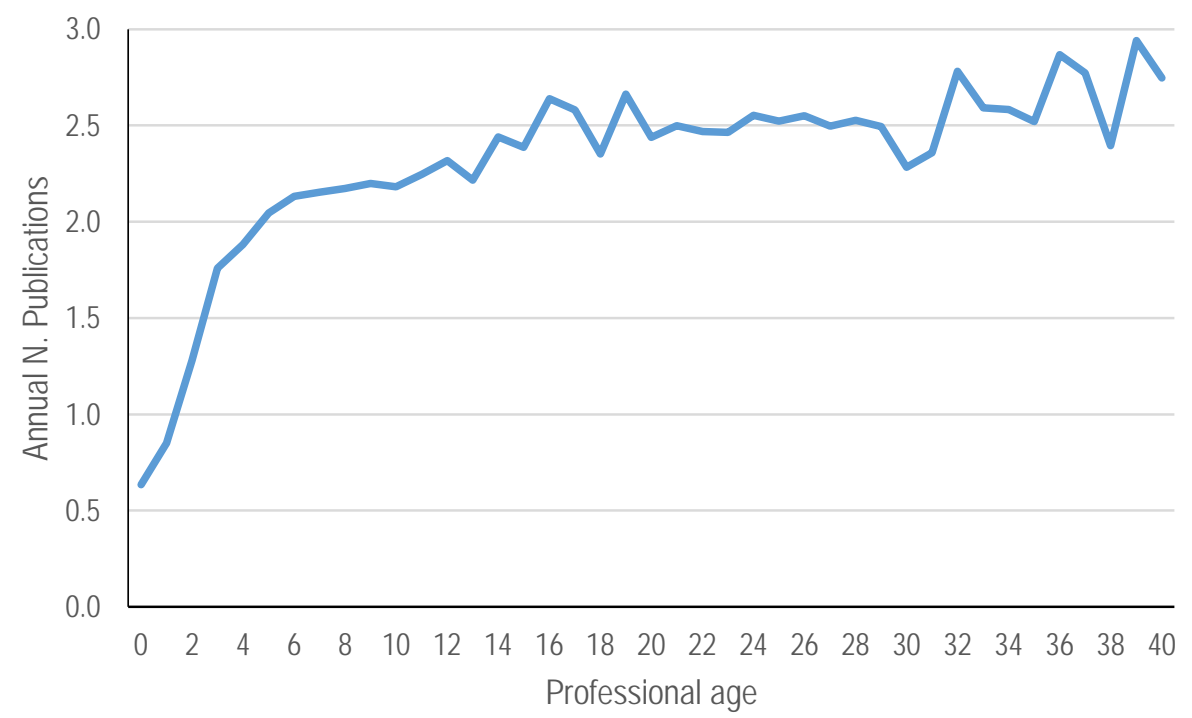

Fig 2 Annual number of publications, by professional age at time of publication

While the above results indicate that there are upward trends with the increase of age when it comes to productivity, they cannot be used to determine its best predictors. Therefore, we performed regression analysis using annual productivity as the dependent variable (Table 2). The results show that there are no statistically significant differences by cohort age or by discipline. In addition, there is no effect of professional age, with the exception of the early years, where productivity increases each year. Women, on average, published 0.5 publications fewer than men (a statistically significant difference) and individuals publish at significantly higher rates at progressively higher ranks. Table 2 demonstrates that, controlling for all other variables, gender and rank are the only significant predictors of productivity.

Table 2. Regression results for productivity

\begin{tabular}{|l|l|l|l|}
\hline Parameter & Estimate & $\begin{array}{l}\text { Std. } \\
\text { Error }\end{array}$ & Sig. \\
\hline Akaike's Information Criterion & 67030.34 & & \\
\hline $\mathrm{n}$ & 814 & & \\
\hline Intercept & 1.953 & 0.259 & 0.000 \\
\hline [Gender=F] & -0.513 & 0.109 & 0.000 \\
\hline [discipline=Economics] & -0.133 & 0.118 & 0.259 \\
\hline [discipline=Political Science] & -0.205 & 0.116 & 0.077 \\
\hline [phddecade=1950's] & 2.120 & 1.054 & 0.045 \\
\hline [phddecade=1960's] & 0.435 & 0.772 & 0.573 \\
\hline [phddecade=1970's] & 0.185 & 0.629 & 0.769 \\
\hline
\end{tabular}




\begin{tabular}{|l|l|l|l|}
\hline [phddecade=1980's] & -0.063 & 0.492 & 0.898 \\
\hline [phddecade=1990's] & -0.151 & 0.355 & 0.671 \\
\hline [phddecade=2000's] & -0.004 & 0.261 & 0.988 \\
\hline Before assistant professor & -1.461 & 0.111 & 0.000 \\
\hline Assistant professor & -0.920 & 0.060 & 0.000 \\
\hline Associate professor & -0.223 & 0.052 & 0.000 \\
\hline prof_age_at_yearT & -0.001 & 0.016 & 0.975 \\
\hline $\begin{array}{l}\text { Percent of variance between } \\
\text { authors (ICC) (\%) }\end{array}$ & 32.546 & & \\
\hline Variance explained & & & \\
\hline Level 1: Within authors (\%) & 70.527 & & \\
\hline Level 2: Between authors (\%) & 29.473 & & \\
\hline
\end{tabular}

\section{Productivity and Genre}

Figure 3 displays the percent of publications produced by authors from each decade in each genre (panel A) and by professional age (panel B). Chi-square tests reveal significant differences $(p<.0001)$ by cohort year (i.e., year of doctoral degree). The most demonstrable difference is in the rising proportion of journal articles in the output of recent doctoral degree recipients. Chi-square tests also show statistically significant differences $(p<.0001)$ in genre production by rank, that is, the rank of the individual at the time of publication. In general, the proportion of output devoted to journal articles decreased across ranks, in favor of a more diversified portfolio (that is, an increase in all other genres). This is not, however, compiled at the level of each individual author; more prolific authors at each rank are overly represented in the genre analysis. Correlations between publications in each genre and professional age at the time of publication reveal statistically significant relationships. Most noticeable is the increasing emphasis on books and book chapters by age (which may be explained by the fact that these are often "invited" pieces). Also typically "invited" are encyclopedia entries, the production of which increases consistently with age. However, none of these increases in production seem to cause a dramatic decrease in the production of journal articles, which remains around 1.4 articles per year for about forty years of professional life. The pattern in terms of conferences is also fairly stable until the end of the career, when a slight increase is witnessed. However, conferences, encyclopedia entries, and dictionary entries remain a small proportion of the overall output of a scholar.
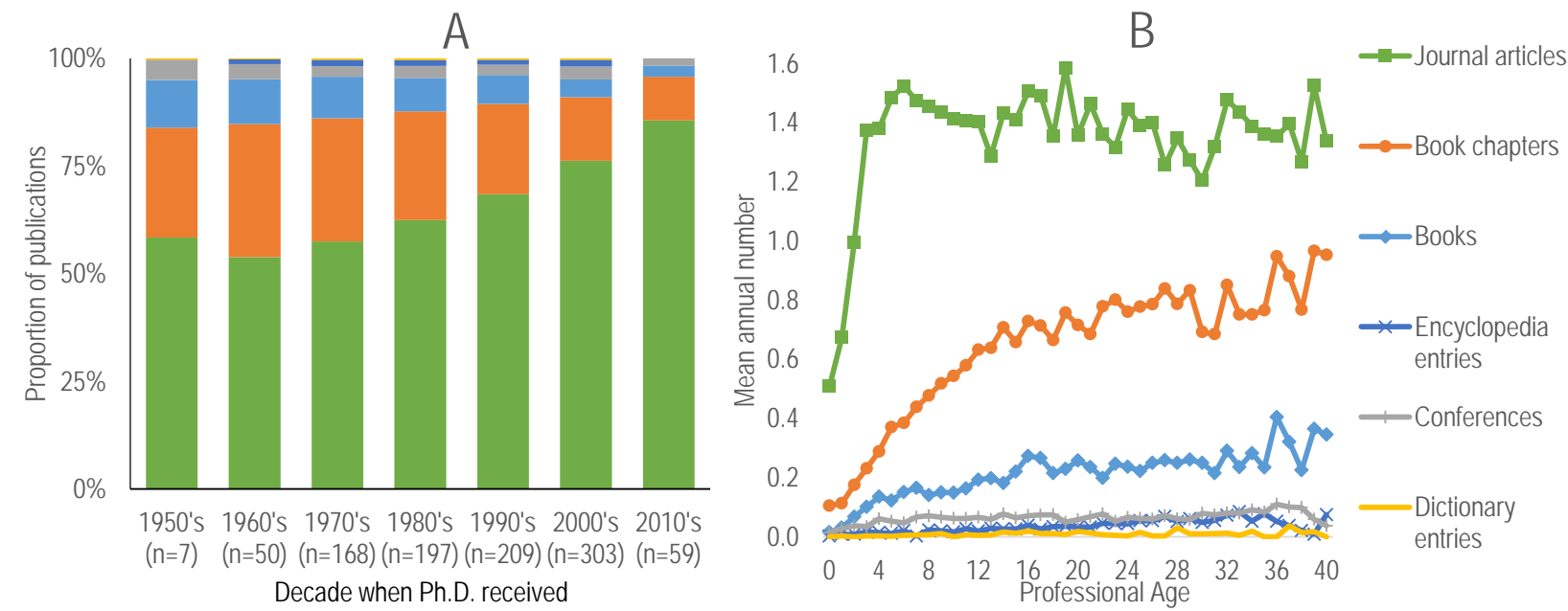

Fig 3 Proportion of publications by genre. A) by decade of doctoral degree, B) by professional age 
There were also statistically significant differences by discipline: Political science and sociology had proportionally more output as books and chapters than economics; Economics had proportionally more journal articles, conference proceedings, and dictionary entries; and Sociology had proportionally more encyclopedia entries than the other two disciplines. There were also statistically significant differences by gender, with women producing proportionally more book chapters, whereas men were producing proportionally more journal articles.

\section{Collaboration and Aging}

Collaboration is one of the staples of modern science. Research teams are becoming more common and are increasing in size. There is a drop in the fraction of single-authored papers (Wuchty et al. 2007) and a shift of team size distributions from small teams ( $<10$ authors) to large, power-law distributed teams (10-1000 authors) (Milojević 2014). However, the relationship between collaborative practices and the lifecycle of scholars has not been previously examined at scale. Our results show that there is a statistically significant difference in proportion of collaboratively authored publications by cohort decade. As shown in Figure 4A, the proportion of works that are collaboratively authored has increased by each cohort year. We find statistically significant differences in collaboration behaviors by rank as well, with Full professors collaborating more than Assistant or Associate professors. Figure 4B shows the average percent of publications that were collaboratively authored while at each rank. However, these results are likely driven by older professors who were Assistant and Associate professors at a time when collaboration was less prevalent.
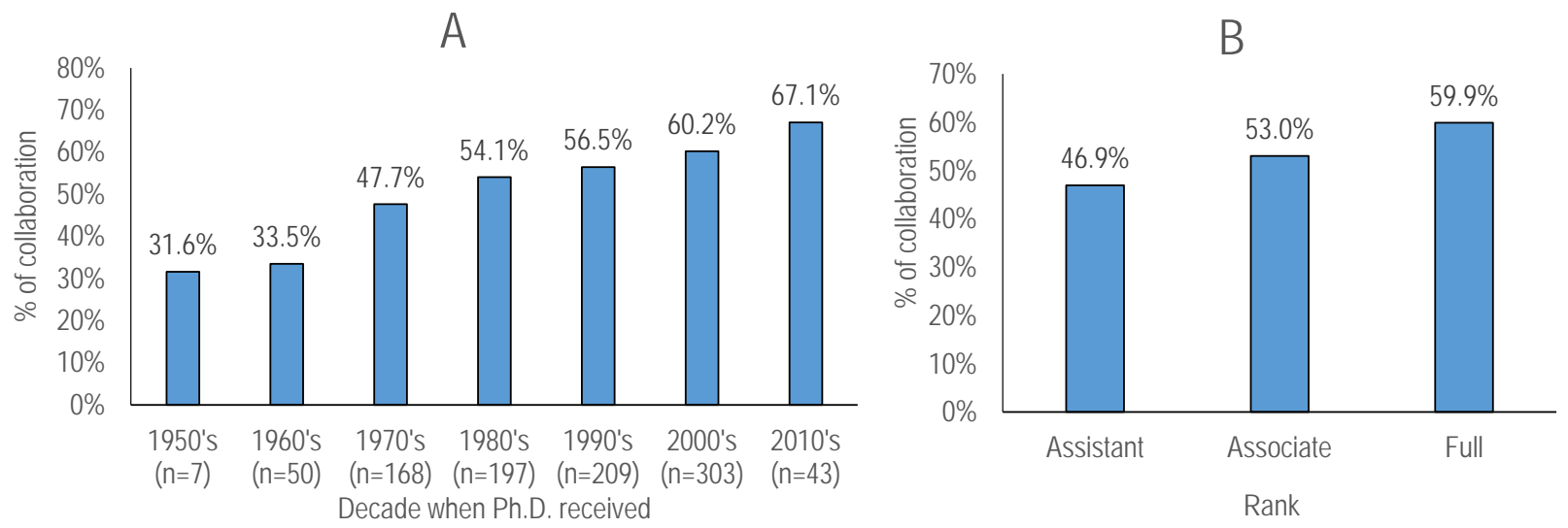

Fig 4 Proportion of collaboratively authored publications. A) by cohort year, B) by professorial rank at time of publication

Figure 5A shows the collaboration rate by year for the middle five cohorts, after removing the first ten years of each professional decade (where there may be fewer authors in some years whose collaboration propensities dominate). We find that although collaboration patterns may be shaped by early experience, collaboration generally becomes relatively more common over time, even within individuals. This is especially the case for the cohorts starting in the 1970's onward. Calculating by professional age (Figure 5B) we show that the least collaborative years are early in the career. By the sixth year of an academic career, the majority of papers are collaboratively authored and collaboration patterns tend to stabilize by this time. As seen above, lower collaboration rates at older professional age likely show the cohort effect (only older cohorts are present at higher professional ages). 

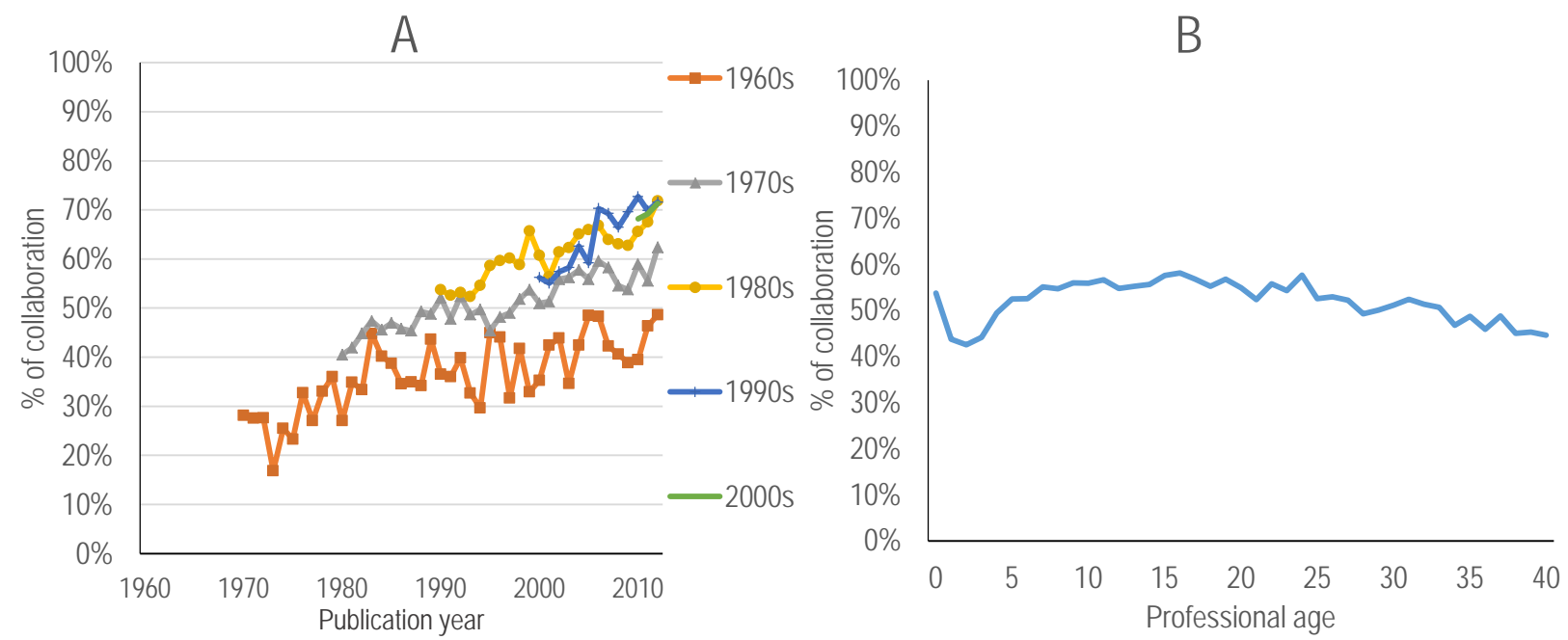

Fig 5 Proportion of collaboratively authored publications, A) by cohort and publication year, B) by professional age

We have also confirmed previous findings that collaboration is field-dependent. Namely, we found statistically significant differences $(p<0.001)$ in the proportion of collaboratively authored publications by discipline with political scientists being the least collaborative and economists the most collaborative. Similarly, we confirmed the differences in collaborative practices by gender where we found that male collaboration rates were significantly $(p<.0001)$ different from female collaboration rates: $58 \%$ of publications from male faculty members were collaboratively authored, while $51 \%$ of publications from female faculty members were collaboratively authored.

We performed regression analysis using collaboration (defined as the percent of publications that were coauthored) as the dependent variable (Table 3). Years were only included when authors had at least one publication. We found that on average, collaboration rates increased with higher ranks (particularly between Assistant and Associate professor). While our previous analysis indicated that individuals from earlier cohorts collaborated less frequently, this factor was not statistically significant. We confirm that collaboration has become more common with time and that women collaborate slightly less frequently than men, although the difference (five percent) may not be meaningful. Collaboration is significantly more prevalent in economics than in sociology, and less common in political science than in sociology. Controlling for all other variables, discipline and rank were the strongest predictors of propensity to collaborate.

Table 3. Regression results for collaboration

\begin{tabular}{|l|l|l|l|}
\hline Parameter & Estimate & $\begin{array}{l}\text { Std. } \\
\text { Error }\end{array}$ & Sig. \\
\hline Akaike's Information Criterion & 9183.39 & & \\
\hline $\mathrm{n}$ & 814 & & \\
\hline Intercept & -16.902 & 6.015 & 0.005 \\
\hline [Gender=F] & -0.049 & 0.021 & 0.019 \\
\hline
\end{tabular}




\begin{tabular}{|l|l|l|l|}
\hline [discipline=Economics] & 0.110 & 0.022 & 0.000 \\
\hline [discipline=Political Science] & -0.083 & 0.021 & 0.000 \\
\hline [phddecade=1950's] & -0.138 & 0.195 & 0.479 \\
\hline [phddecade=1960's] & -0.146 & 0.146 & 0.318 \\
\hline [phddecade=1970's] & -0.046 & 0.121 & 0.703 \\
\hline [phddecade=1980's] & -0.054 & 0.097 & 0.575 \\
\hline [phddecade=1990's] & -0.045 & 0.074 & 0.547 \\
\hline [phddecade=2000's] & -0.027 & 0.060 & 0.654 \\
\hline Before assistant professor & -0.140 & 0.027 & 0.000 \\
\hline Assistant professor & -0.140 & 0.013 & 0.000 \\
\hline Associate professor & -0.048 & 0.011 & 0.000 \\
\hline prof_age_at_yearT & -0.005 & 0.003 & 0.070 \\
\hline Year & 0.009 & 0.003 & 0.003 \\
\hline $\begin{array}{l}\text { Percent of variance between } \\
\text { authors (ICC) (\%) }\end{array}$ & 33.164 & & \\
\hline Variance explained & & & \\
\hline Level 1: Within authors (\%) & 72.259 & & \\
\hline Level 2: Between authors (\%) & 27.741 & & \\
\hline
\end{tabular}

\section{Aging and scientific impact}

In this study we focused on two measures of impact: mean journal IF and mean paper citation rates (ARC), both compiled at the level of individuals. In a manner similar to productivity, we first examined the relationship between these two measures of impact and three types of operationalization for age: cohort, rank, and professional age. In addition, we carried out regression analyses to determine the best predictors for the two measures of impact. Our results indicate that there are significant differences in impact by cohort, both in terms of the mean IF for the journals in which researcher's published and the mean ARC of their papers (Figure 6A). While mean IF was highest for those who graduated in the 1980s, the highest mean ARC was obtained by those who graduated in earlier decades. The discrepancy between IFs and citations suggest the existence of a Matthew Effect, where scholars from younger generations manage to publish in better journals, but their papers receive lower recognition (Merton 1968).

When it comes to rank (Figure 6B), Assistant Professors publish, on average, in journals of the highest IF, yet the difference is not statistically significant. Associate professors yielded the highest ARC, yet this difference is also not statistically significant. Analysis by professional age at the time of publication demonstrates that the IF is fairly static across a career, while the ARC peaks in the early years and then continually declines (Figure $6 \mathrm{C}$ ). While there were no significant differences in productivity among researchers from different disciplines, we found that there were significant differences in IF by discipline. Namely, highest impact factors are in Economics (mean=2.24; SD: 1.39), followed by Political Science (mean=2.12; SD; 1.45), with Sociology as the lowest IF in the set (mean=2.06; SD=1.43). The average ARC for economists was highest and for sociologists the lowest; however, these differences were not significant (at the $p<.0001$ level). 
A

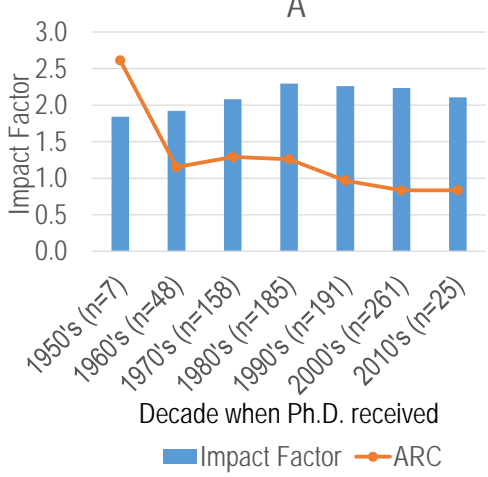

B

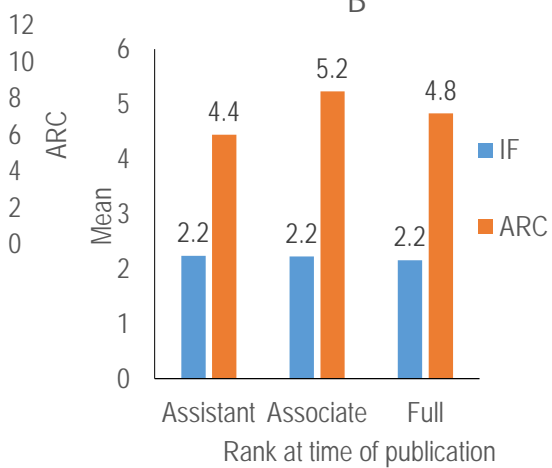

C

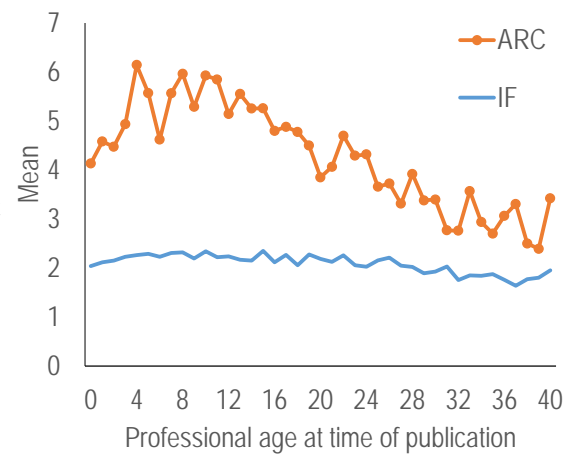

Fig 6 Scientific impact measures. A) By decade of receipt of the doctoral degree, B) by professorial rank at time of publication, $C$ ) by professional age at time of publication

We performed regression analysis using the Impact Factor (defined as the average impact factor of the publications' journals for each year) as the dependent variable. Years were only included when authors had at least one publication with an Impact Factor. We did not find significant differences for Ph.D. cohorts, although that may be caused by a lack of precision in the estimates. However, on average, the Impact Factor is lower in the time before earning Associate rank and appears to peak during this time. Following promotion to Full professor, the Impact Factor gradually declines with age. Regression analysis also shows disciplinary differences with economists' publications generally published in higher impact journals than those of political scientists' or sociologists'.

Table 4. Regression results for Impact Factor

\begin{tabular}{|l|l|l|l|}
\hline Parameter & Estimate & $\begin{array}{l}\text { Std. } \\
\text { Error }\end{array}$ & Sig. \\
\hline Akaike's Information Criterion & 21951.84 & & \\
\hline $\mathrm{n}$ & 814 & & \\
\hline Intercept & 2.123 & 0.251 & 0.000 \\
\hline [Gender=F] & -0.048 & 0.066 & 0.465 \\
\hline [discipline=Economics] & 0.289 & 0.065 & 0.000 \\
\hline [discipline=Political Science] & 0.038 & 0.068 & 0.577 \\
\hline [phddecade=1950's] & 0.533 & 0.596 & 0.372 \\
\hline [phddecade=1960's] & 0.405 & 0.469 & 0.388 \\
\hline [phddecade=1970's] & 0.398 & 0.399 & 0.319 \\
\hline [phddecade=1980's] & 0.273 & 0.334 & 0.414 \\
\hline [phddecade=1990's] & 0.269 & 0.277 & 0.333 \\
\hline [phddecade=2000's] & 0.228 & 0.243 & 0.349 \\
\hline Before assistant professor & -0.341 & 0.151 & 0.024 \\
\hline Assistant professor & -0.299 & 0.078 & 0.000 \\
\hline Associate professor & -0.160 & 0.099 & 0.107 \\
\hline prof_age_at_yearT & -0.026 & 0.009 & 0.005 \\
\hline $\begin{array}{l}\text { Before assistant professor * } \\
\text { prof_age_at_yearT }\end{array}$ & 0.137 & 0.092 & 0.137 \\
\hline & & & \\
\hline
\end{tabular}




\begin{tabular}{|l|l|l|l|}
\hline $\begin{array}{l}\text { Assistant professor * } \\
\text { prof_age_at_yearT }\end{array}$ & 0.054 & 0.015 & 0.000 \\
\hline $\begin{array}{l}\text { Associate professor * } \\
\text { prof_age_at_yearT }\end{array}$ & 0.009 & 0.011 & 0.397 \\
\hline $\begin{array}{l}\text { Percent of variance between } \\
\text { authors (ICC) (\%) }\end{array}$ & 16.134 & & \\
\hline Variance explained & 83.933 & & \\
\hline Level 1: Within authors (\%) & 16.067 & & \\
\hline Level 2: Between authors (\%) & 163 & & \\
\hline
\end{tabular}

We also carried out regression analysis for ARC, using the average ARC for each publication in each year as the dependent variable. Years were only included when authors had at least one publication with an ARC. Publications by assistant professors have lower average ARCs than those by associate or full professors. The relationship between ARC and professional age appears to be negative, although it is not statistically significant in the regression, which may be due to the lack of precision in estimates.

Table 5. Regression results for ARC

\begin{tabular}{|l|l|l|l|}
\hline Parameter & Estimate & $\begin{array}{l}\text { Std. } \\
\text { Error }\end{array}$ & Sig. \\
\hline Akaike's Information Criterion & 53890.91 & & \\
\hline $\mathrm{n}$ & 814 & & \\
\hline Intercept & 4.754 & 2.013 & 0.018 \\
\hline [Gender=F] & -0.418 & 0.487 & 0.391 \\
\hline [discipline=Economics] & 0.605 & 0.472 & 0.200 \\
\hline [discipline=Political Science] & 0.687 & 0.495 & 0.166 \\
\hline [phddecade=1950's] & 7.431 & 4.395 & 0.091 \\
\hline [phddecade=1960's] & -0.071 & 3.516 & 0.984 \\
\hline [phddecade=1970's] & 1.225 & 3.020 & 0.685 \\
\hline [phddecade=1980's] & 0.177 & 2.565 & 0.945 \\
\hline [phddecade=1990's] & -0.115 & 2.175 & 0.958 \\
\hline [phddecade=2000's] & -0.080 & 1.948 & 0.967 \\
\hline Before assistant professor & -2.769 & 1.041 & 0.008 \\
\hline Assistant professor & -1.668 & 0.469 & 0.000 \\
\hline Associate professor & -0.597 & 0.412 & 0.147 \\
\hline prof_age_at_yearT & -0.108 & 0.070 & 0.123 \\
\hline $\begin{array}{l}\text { Percent of variance between } \\
\text { authors (ICC) (\%) }\end{array}$ & 9.855 & & \\
\hline Variance explained & & & \\
\hline Level 1: Within authors (\%) & 90.693 & & \\
\hline
\end{tabular}




\begin{tabular}{|l|l|l|l|}
\hline Level 2: Between authors (\%) & 9.307 & & \\
\hline
\end{tabular}

\section{DISCUSSION}

This study has provided a comprehensive analysis of aging and scholarly communication behavior and metrics for faculty members in the social sciences currently serving at elite institutions. The data suggests a significant relationship between rank and productivity, where scholars in higher ranks are more productive. In general, the data suggests that these faculty members maintain productivity levels for forty years-spanning an academic lifecycle-and do not decline as they age. Gender differences were observed for productivity.

Not only are Full professors the most productive, but they also have the most diverse portfolio of genres for disseminating their findings. Namely, as they advance in ranks, researchers tend to add books and book chapters, while maintaining their levels of production of journal articles. This corresponds to Sabharwal's (2013a) finding of the production of books in later stages, but does not reinforce her finding of the peaking in journal article production in the midcareer stage. Our analysis of genres showed an increasing focus on journal articles, especially among Assistant professors. At the same time, there were significant differences in genres used by both discipline and by gender. We found that journal articles comprise the most frequent unit of publication across all ranks, although the share of journal articles decreases across ranks with a corresponding increase in books and book chapters. Thus, it may seem that rank rather than cohort informs the choice of genre. Namely, it is hardly surprising that assistant professors who are working on obtaining tenure favor journal articles: Journal articles are quicker to produce than books and may carry more weight with university Promotion and Tenure committees who may be used to thinking in terms of journals and associated metrics. On the other hand, it is also not surprising that Full professors produce so many book chapters: book chapters are often written by invitation, and full professors at leading institutions would be expected to be invited to make contributions to this literature.

Studies have shown that science is becoming more collaborative. Thus, one may expect that younger scholars are more open to this mode of scientific production. However, we found that the propensity to collaborate increased over time and by rank, with significant differences by discipline and gender. Overall, rank was shown to be the best predictor of changes in scholarly communication practices and metrics, suggesting that future studies should focus on this variable when operationalizing aging.

Impact metrics also tend to be higher by rank and in certain disciplines. There appears to be a peak in ARC around tenure. Previous studies found gender disparities in both production and impact to be persistent in contemporary science (Long 1992; Larivière, Ni, Gingras, Cronin, and Sugimoto 2013). However, while our study identified significant differences in productivity, collaboration behaviors, and genre production by gender, there were not significant differences by gender in impact.

Limitations. There is a strong relationship between performance on scientometric metrics and organizational context (Allison and Long 1990). Given that these are institutions with high prestige, we can expect that faculty at these institutions will be more productive and more cited than individuals at lower ranked institutions. Therefore, given the purposive nature of sampling, these results are not generalizable to the entire spectrum of academic institutions. The sampling frame (choosing individuals still in academe) leaves results open to survival bias. The reasons for differences may be due to the fact that individuals who remain in academe are systemically different from those that left (and thus, not included in the sample). 
Furthermore, although CVs provide the possibility for analysis between aging and scientometric variables, our study encountered many of the limitations detailed in Dietz et al.'s (2000) description of using CVs to study career paths. As self-report nature, these documents are often missing information or not up-to-date. They are also not available for all faculty members. Furthermore, as we noted earlier, many scholars only provided the date at which they obtained their latest rank, which made analysis of previous ranks more difficult. There were also differences in how different genre types and collaboration were reported, which complicates comparative analysis. The growing use of social media platforms as real-time CVs may mitigate some of these issues for contemporary analyses.

\section{CONCLUSION AND FUTURE DIRECTIONS}

Our research suggests that changes in scholarly communication patterns are more due to career aging (rank) than to cohort changes: that is, that changes were more likely to occur with changes in academic status than in mere passage of time. The data did not reflect significant changes in productivity, genre choice, or collaboration from those who received their degrees in the 1960 s to the present. However, there were marked differences in productivity by rank-productivity of researchers in all three fields increased rather than decreased with rank, suggesting that social sciences may not be the "young man's game" that many scientific disciplines are made out to be (Merton and Zuckerman 1972). However, this study is limited by looking at faculty members only in elite institutions of one discipline. To increase the robustness of the study, the sample should be enhanced to show variability in institutions and disciplines. Future work should continue to test various models of aging in order to understand more fully the intersection among temporal, social, and individual factors of scientific achievement. Furthermore, other variables - such as resources available to the faculty member (including grants, students, and other factors) should be analyzed.

\section{ACKNOWLEDGEMENTS}

This work was funded by the Science of Science Innovation and Policy (SciSIP) program of the National Science Foundation (grant no. 1158670). The authors would also like to thank Chaoqun Ni and Ying Ding for contributions to earlier drafts of this work.

\section{CITED REFERENCES}

Abramo, G., D'Angelo, C. A., \& Murgia, G. (2015). The combined effects of age and seniority on research performance of full professors. Science and Public Policy, scv037.

Allison, P. D., \& Stewart, J. A. (1974). Productivity differences among scientists: Evidence for accumulative advantage. American Sociological Review, 39(4), 596-606.

Allison, P. D., Long, J. S., \& Krauze, T. K. (1982). Cumulative advantage and inequality in science. American Sociological Review, 47(5), 615-625.

Allison, P.D., \& Long, J.S. (1990). Departmental effects on scientific productivity. American Sociological Review, 55(4), 469-478.

Archambault, É., Vignola Gagné, É., Côté, G., Larivière, V., \& Gingras, Y. (2006). Benchmarking scientific output in the social sciences and humanities: The limits of existing databases. Scientometrics, 68(3), 329-342.

Bayer, A.E., \& Smart, J.C. (1991). Career publication patterns and collaborative "styles" in American academic science. The Journal of Higher Education, 62(6), 613-636.

Bernier, C.L., Gill, W.N., \& Hunt, R.G. (1975). Measures of excellence of engineering and science departments: a chemical engineering example. Chemical Engineering Education, 194-197.

Blackburn, R. T., \& Lawrence, J. H. (1986). Aging and the quality of faculty job performance. Review of Educational Research, 56(3), 265-290. 
Chi, P. S. (2014). Which role do non-source items play in the social sciences? A case study in political science in Germany. Scientometrics, 101(2), 1195-1213.

Cole, S. (1979). Age and scientific performance. American Journal of Sociology, 84(4), 958-977.

Corley, E. A., \& Sabharwal, M. (2010). Scholarly collaboration and productivity patterns in public administration: Analysing recent trends. Public Administration, 88(3), 627-648.

Cronin, B., \& Meho, L.I. (2007). Timelines of creativity: A study of intellectual innovators in information science. Journal of the American Society for Information Science \& Technology, 58(13), 19481959.

Diamond, A.M. (1986). The life-cycle research productivity of mathematicians and scientists. Journal of Gerontology, 41, 520-525.

Dietz, J.S., Chompalov, I., Bozeman, B., O’Neil Lane, E., \& Park, J. (2000). Using the curriculum vita to study the career paths of scientists and engineers: An exploratory assessment. Scientometrics, 49(3), 419-442.

Dubois, P., Rochet, J. C., \& Schlenker, J. M. (2014). Productivity and mobility in academic research: Evidence from mathematicians. Scientometrics, 98(3), 1669-1701.

Endenich, C., \& Trapp, R. (2015). Cooperation for Publication? An Analysis of Co-authorship Patterns in Leading Accounting Journals. European Accounting Review, 1-21.

Fox, M. F., \& Faver, C. A. (1984). Independence and cooperation in research: The motivations and costs of collaboration. Journal of Higher Education, 55, 347-359.

Gingras, Y., Larivière, V., Macaluso, B., \& Robitaille, J. P. (2008). The effects of aging on researchers' publication and citation patterns. PloS One, 3(12), e4048.

Gonzalez-Brambila, C., \& Veloso, F. M. (2007). The determinants of research output and impact: A study of Mexican researchers. Research Policy, 36, 1035-1051.

Hu, Z., Chen, C., \& Liu, Z. (2014). How are collaboration and productivity correlated at various career stages of scientists? Scientometrics, 101(2), 1553-1564.

Jones, B.F. (2005). Age and great invention. NBER Working Paper No. 11359.

Larivière, V., Archambault, É., Gingras, Y., \& Vignola Gagné, É. (2006). The place of serials in referencing practices: Comparing natural sciences and engineering with social sciences and humanities. Journal of the American Society for Information Science and Technology, 57(8), 997-1004.

Larivière, V., Ni, C., Gingras, Y., Cronin, B., \& Sugimoto, C.R. (2013). Global gender disparities in science. Nature, 504(7479), 211-213.

Larivière, V., Sugimoto, C.R., Tsou, A., \& Gingras, Y. (2015). Team Size Matters: Collaboration and scientific impact since 1900. Journal of the Association for Information Science and Technology, 66(7), 1323-1332.

Lehman, H.C. (1953). Age and achievement. Princeton, NJ: Princeton University Press.

Long, J. S. (1992). Measures of sex differences in scientific productivity. Social Forces, 71(1), 159-178.

Long, J. S., \& Fox, M. F. (1995). Scientific careers: Universalism and particularism. Annual Review of Sociology, 45-71.

Long, J. S., \& McGinnis, R. (1981). Organizational context and scientific productivity. American sociological review, 422-442.

Long, J. S., Allison, P. D., \& McGinnis, R. (1993). Rank advancement in academic careers: Sex differences and the effects of productivity. American Sociological Review, 58(5), 703-722.

Long, J.S., McGinnis, R., \& Allison, P.D. (1980). The problem of junior-authored papers in constructing citation counts. Social Studies of Science, 10(2), 127-143.

Mählck, P. (2001). Mapping gender differences in scientific careers in social and bibliometric space. Science, Technology, \& Human Values, 26(2), 167-190.

Merton, R. K. (1968). The Matthew effect in science. Science, 159(3810), 56-63. 
Merton, R.K., \& Zuckerman, H. (1972). Age, aging, and age structure in science. In N.W. Storer (Ed), The sociology of science: Theoretical and empirical investigations. Chicago, IL: University of Chicago Press.

Milojević, S. (2012). How are academic age, productivity and collaboration related to citing behavior of researchers? PLoS ONE, 7(11), e49176.

Milojević, S. (2014). Principles of scientific research team formation and evolution. Proceedings of the National Academy of Sciences (PNAS), 111(11), 3984-3989.

Nederhof, A., van Leeuwen, T., \& van Raan, A. (2009). Highly cited non-journal publications in political science, economics and psychology: a first exploration. Scientometrics, 83(2), 363-374.

Nederhof, A.J. (2006). Bibliometric monitoring of research performance in the Social Sciences and the Humanities: A review. Scientometrics, 66(1), 81-100.

O’Brien, T.L. (2011). Change in academic coauthorship, 1953-2003. Science, Technology \& Human Values, 37(3), 210-234.

Oromaner, M. (1977). Professional age and the reception of sociological publications: A test of the Zuckerman-Merton hypothesis. Social Studies of Science, 7, 381-388.

Oster, S.M., \& Hamermesh, D. S. (1998). Aging and productivity among economists. The Review of Economics and Statistics, 80(1), 154-156.

Over, R. (1988). Does scholarly impact decline with age? Scientometrics, 13, 207-215.

Over, R. (1989). Age and scholarly impact. Psychology and Aging, 4(2), 222-225.

Planck, M. (1949). Scientific autobiography and other papers. New York: Philosophical Library.

Prozesky, H, \& Boshoff, N. (2011) Bibliometrics as a tool for measuring gender-specific research performance: an example from South African invasion ecology. Scientometrics, 90(2), 383-406.

Sabharwal, M. (2013a). Comparing research productivity across disciplines and career stages. Journal of Comparative Policy Analysis: Research and Practice, 15(2), 141-163.

Sabharwal, M. (2013b). Productivity and leadership patterns of female faculty members in public administration. Journal of Public Affairs Education, 73-96.

Shaw, D., \& Vaughan, L. (2008). Publication and citation patterns among LIS faculty: Profiling a "typical professor." Library \& Information Science Research, 30(1), 47-55.

Simonton, D.K. (1988). Age and outstanding achievement: What do we know after a century of research? Psychological Bulletin, 104(2), 251-267.

Stephan, P. E. (1996). The economics of science. Journal of Economic Literature, 34(3), 1199-1235.

Sugimoto, C.R., \& Cronin, B. (2012). Bio-bibliometric profiling: An examination of multi-faceted approaches to scholarship. Journal of the American Society for Information Science \& Technology, 63(3), 450-468.

Sugimoto, C.R., Russell, T.G., Meho, L.I., \& Marchionini, G. (2008). MPACT and citation impact: Two sides of the same scholarly coin? Library \& Information Science Research, 30(4), 273-281.

van Arensbergen, P., van der Weijden, I., \& Van den Besselaar, P. (2012). Gender differences in scientific productivity: a persisting phenomenon? Scientometrics, 93(3), 857-868.

Whitley, R. (2000). The intellectual and social organization of the sciences (2nd ed.). Oxford: Oxford University Press.

Wuchty, S., Jones, B.F., Uzzi, B. (2007). The increasing dominance of teams in production of knowledge. Science 316(5827):1036-1039.

Zuckerman, H. (1987). Persistence and change in the careers of men and women scientists and engineers. In L.S. Dix (Ed.), Women: Their underrepresentation and career differentials in science and engineering (pp. 127-156). Washington, D.C.: National Academy Press. 